\title{
С.В. Сотникова
}

\section{К ВОПРОСУ ОБ АНТРОПОМОРФИЗАЦИИ КРЕМИРОВАННЫХ ОСТАНКОВ В ПОГРЕБАЛЬНОМ ОБРЯДЕ НАСЕЛЕНИЯ АНДРОНОВСКОЙ КУЛЬТУРНО-ИСТОРИЧЕСКОЙ ОБЩНОСТИ}

\begin{abstract}
Исследуется андроновский ритуал кремации умершего. Кремация уничтожала облик человека, поэтому для воссоздания разрушенного огнем образа андроновское население использовало различные способы антропоморфизации кремированных останков, такие как создание погребальной «куклы»; заворачивание в одежду умершего; помещение в могилу украшений как самостоятельного элемента костюма; захоронение кремированных останков в сосуде. Антропоморфизированные различным образом кремированные останки, вероятно, рассматривались как вместилище души покойного.

Ключевые слова: бронзовый век; андроновская культурно-историческая общность; погребальный обряд; кремация; антропоморфизация.
\end{abstract}

Одним из ярких элементов погребального обряда андроновского (федоровского) населения являлся ритуал сожжения умершего. Андроновская культурноисторическая общность занимала в эпоху бронзы обширные пространства степной и лесостепной зоны Южного Урала, Казахстана и Западной Сибири. Большинство исследователей считают, что в эту общность входили две самостоятельные культуры - алакульская и федоровская, которые на определенном этапе своего развития сосуществовали и оказывали взаимное влияние друг на друга. Вопрос об этнической принадлежности андроновского населения является спорным. Е.Е. Кузьмина [1. С. 116] и многие другие исследователи относят всех андроновцев, федоровцев и алакульцев к индоиранцам. Это позволяет привлекать для интерпретации андроновского материала письменные источники народов, имеющих индоевропейские корни (древнеиранские, индоарийские, хеттские, древнегреческие и т.д.). Опираясь на данные древних письменных источников, представляется возможным реконструировать некоторые элементы андроновского обряда кремации и связанные с ним представления.

Погребальный обряд федоровского населения западных и восточных районов имеет существенные различия. Кремация являлась характерной чертой погребального ритуала андроновского (федоровского) населения западных районов, прежде всего Южного Зауралья. В восточных районах преобладающим способом захоронения являлась ингумация, а погребения с сожжением были немногочисленны. Исключение составляют некоторые могильники Западной Сибири (Ур и т.п.). Отдельные погребения с кремацией представлены также на тех памятниках восточного региона, где в керамическом материале наблюдается смешение алакульской и федоровской традиций.

Обряд кремации производился на стороне, а в погребение помещались компактные скопления кальцинированных костей. Они располагались, как правило, в центральной или восточной части могильной ямы. В западной половине обычно находились сосуды и кости животных (ребра). Материалы андроновских погребений с остатками кремации интересны тем, что позво- ляют проследить появление различных способов антропоморфизации кремированных останков. Можно выделить три основных варианта.

Вариант 1. Кремированные останки расположены в виде компактных скоплений в сопровождении украшений. В некоторых могилах среди или рядом с остатками кремации обнаружены бронзовые украшения, которые представлены двумя основными видами. Во-первых, украшения, связанные с декором одежды, во-вторых, украшения, являющиеся самостоятельным элементом костюма.

В западных районах распространения населения андроновской культурно-исторической общности погребения, в которых кремированные останки сопровождаются украшениями, происходят в основном из могильников со смешанной алакульско-федоровской керамикой. В Центральном Казахстане погребения с кремацией и украшениями встречены как на памятниках атасуского типа (Бегазы, Ельшибек, Шет-I, Атасу-I), которые Е.Е. Кузьмина относит к категории смешанных (алакульско-федоровских) типов алакульской линии развития [2. С. 42], так и в нуринских (федоровских). На территории Западной Сибири такие погребения относятся к федоровской культуре.

Некоторые атасуские комплексы Центрального Казахстана, в которых встречены украшения, содержат следы неполного трупосожжения. В могильнике Бегазы в северном ящике ограды 11 «отдельные фрагменты костей сохранили следы огня», среди разбросанных костей обнаружены обломок бронзовой привески и несколько пастовых бусин и пронизок. В комплексе Ельшибек в ящике 4 ограды 73 на дне и в заполнении встречались мелкие кости человека, причем на некоторых костях имелись следы огня. В могиле найдены бронзовая бусина биконической формы, костяная трехгранная пронизка с резным орнаментом, спекшиеся бронзовые пластинки. В ящике 5 той же ограды на дне и в заполнении найдены разрозненные кости человека, среди них - одна пережженная кость и несколько кальцинированных косточек, а также обнаружены бронзовая и аргиллитовая бусины [3. С. 132, 138, 140]. В могильнике Шет-I ограда 3 содержала три примыкающих 
друг к другу каменных ящика, содержавших остатки кремации. В этих погребениях найдены 5 бронзовых подвесок в 1,5 оборота, обернутых золотой фольгой, две круглые бронзовые бляшки, фрагменты желобчатого браслета с конусовидными спиральными окончаниями [4. С. 89-90, 105].

Находки украшений в погребениях с сожжением характерны также для федоровских памятников Казахстана. В Центральном Казахстане они представлены в андроновских (нуринских) погребениях. В расположении остатков кремации, украшений и другого инвентаря прослеживаются те же закономерности, что и в атасуских. В ограде 1 могильника Сангру-II в могиле 1 находился слой полупережженных костей погребенного, среди которых обнаружены четыре чеканных полушарных бронзовых бляшки с отверстием в центре и по краям, две пронизи из спаянных бронзовых бусин и кусочек фаланговой кости животного с отверстием. В могиле 7 ограды 1 в слое полупережженных костей находились 64 бронзовые бусины. В могиле из ограды 5 рядом с сосудами обнаружены два бронзовых кольца с раструбом, два браслета с длинными спиральными коническими навершиями, обломки бронзового браслета и две плоские бусины. В западной половине ямы зафиксирован слой красной краски вперемежку с полусожженными костями погребенного. В могильнике Бугулы-I в погребениях с сожжением также обнаружены украшения, но их местоположение точно не указывается. В могиле из ограды 1 найдена бронзовая пронизка, в могиле ограды 3 - около 50 бронзовых бусин и круглое бронзовое зеркало, в могиле 2 ограды 4 - около 50 бронзовых пронизок [3. С. 73, 75-76, 100-102].

В Лисаковском-I могильнике в погребении из ограды 3 (группа А, подгруппа 1а) в заполнении вместе с кальцинированными костями обнаружена бронзовая лапчатая подвеска. В погребении 3 ограды Б (группа А, подгруппа 1а) этого же могильника обнаружено биритуальное захоронение. В центре ямы находилась округлая линза кальцинированных костей, рядом с которой - два бронзовых браслета с высокими спиралевидными окончаниями. В северо-восточном углу фрагментарно сохранившиеся кости рук скелета ребенка, на них - по одному бронзовому пластинчатому браслету [5. С. 16, 21].

В могильнике Кожа-Бала в погребении 1 из сооружения 1 остатки кремации сопровождались бронзовым браслетом с конусовидными окончаниями [6. С. 27].

Особенно часто украшения встречаются в погребениях с кремацией в могильнике Боровое (Северный Казахстан). В могиле из ограды 2 среди пережженных костей обнаружены две бронзовые серьги, выпуклая бронзовая бляшка, обломки продолговатой подвески, круглой бляшки, створки раковины. В могиле из ограды 3 среди пережженных костей найдены три выпуклые бронзовые бляшки, две удлиненной формы и одна в форме лапчатой подвески. В могиле из ограды 4 среди пережженных костей обнаружены бронзовая бляшка с выпуклостями по краю, обломок бронзовой бляшки сердцевидной формы. В могиле 1 ограды V, содержащей остатки кремации, у южной стенки найдены две бронзовые серьги. В могиле из ограды 7 среди пережженных костей найден кусочек бронзы. В могиле с кремацией из пристройки 2 к ограде 10 обнаружены две бронзовые серьги и две бронзовые подвески с выпуклостями. В ограде IV останков погребенного не обнаружено, но у западной стенки стоял сосуд, а в центре ямы найдена пара серег с раструбом и 9 бронзовых бляшек с отверстиями для нашивки [7. С. 227, 230-233, $235,236]$. Достаточно широко представлены подобные погребения с кремацией и украшениями на памятниках таутаринского и семиреченского типов (Южный Казахстан и северная часть Средней Азии) по классификации Е.Е. Кузьминой [2. С. 42-43]. Так, в могильнике Тегирмен-Сай в погребении с кремацией из ограды 13 обнаружены бронзовая бусина и бронзовая серьга с раструбом [8. С. 9]. Встречены подобные погребения также в могильниках Тау-Тары, Таш-Тюбе, Таш-Башат [9. С. 83-93; 10. С. 37-38]. Представлены они и в Южном Зауралье. В яме 3 кургана 2 могильника КулевчиVI поверх кальцинированных костей лежали два бронзовых браслета [11. С. 140-141].

Известны такие комплексы и на территории Западной Сибири. В могильнике у с. Титово (Кузнецкая котловина) в могиле из кургана 1 , содержащей остатки кремации, около северо-восточной стенки лежали кольчатые бусы. В могиле с кремацией из кургана 10 могильника Ур рядом с сосудами лежали два бронзовых височных кольца [12. С. 11, 34]. В могильнике Рублево-VIII могила 45 содержала кремированные останки, пастовые пронизки, браслеты со спиралевидными окончаниями [13. С. 64, 68]. В могиле-1 могильника Нижняя Суетка в слое кремированных костей найдены две золотые кольчатые серьги [14. С. 85]. В могильнике Фирсово-XIV из 130 погребений всего два содержали остатки кремации, причем в сопровождении украшений. В могиле 104 обнаружены остатки кремации и четыре подвески в 1,5 оборота. Могила- 222 представляла собой биритуальное захоронение мужчины 20-25 лет, скорченно, на левом боку и остатков кремации перед лицевой частью скелета. Сверху на кремированных останках лежали четыре бронзовых браслета, два биспиральных бронзовых кольца, восемь подвесок в 1,5 оборота. По краю кремации протянулись два ряда бронзовых бус (около 50 штук), которые оканчивались двумя накосниками с пунсонным орнаментом. Около правой голени обнаружен комплекс украшений, являющийся частью женского головного убора (золотые трубочки-пронизки, гофрированные обоймы, подвеска в виде конуса) и два трубчатых золотых кольца, сцепленных между собой [15. С. 51-52].

Имеются также коллективные захоронения с четким разделением кремированных костей на отдельные скопления. В могиле Б ограды 14 могильника Боровое обнаружено парное погребение по способу трупосо- 
жжения. Скопления костей обнаружены в середине северо-западной и юго-восточной стенок. С северозападным скоплением связана одна бронзовая бляшка, выпуклая, овальной формы с выпуклостями. Со вторым скоплением связаны две бронзовые бляшки с отверстиями для нашивки (одна ромбическая, другая круглая с крестообразно расположенными выпуклостями в середине), две бронзовые серьги с раструбом, 75 бронзовых бусин [7. С. 223]. В могиле из курганаограды 39 могильника Атасу-I зафиксированы три скопления кальцинированных костей, охра. Здесь же обнаружены бронзовые и пастовые бусы, две бронзовые нашивные бляшки с двумя отверстиями для крепления и лапчатая подвеска [4. С. 107]. В могильнике Путиловская Заимка-II (курган 7) на дне у восточной стены обнаружены два скопления кальцинированных костей, у западной - три сосуда, лопаточная кость животного, бронзовый нож с перехватом и два бронзовых разомкнутых височных кольца, обернутых золотой фольгой [16. С. 99]. В алакульско-федоровском могильнике Солнце-Талика захоронение в кургане 2 содержало три скопления кальцинированных костей, а из заполнения могилы и норы извлечены обломки бронзовых украшений, в частности височного кольца или браслета выпукло-вогнутого сечения [17. С. 133-134].

Наиболее выразительная картина зафиксирована в алакульско-федоровском погребении 2 кургана 3 могильника Кулевчи-VI (Южное Зауралье [11. С. $142-$ 145]. В этом погребении в восточной части дна находились два скопления кальцинированных костей, с каждым из которых был связан комплекс украшений. Скопление 1 имело неправильные, вытянутые с югозапада на северо-восток, очертания. Непосредственно на слое кальцинированных костей располагались детали накосника: две ленты бронзовых обойм с крупной обоймой на одном конце и с листовидными бронзовыми привесками на другом. У северо-восточного окончания этого скопления зафиксированы две низки бронзовых бус, аналогичные низкам бус на нижних окончаниях берцовых костей, погребенных по способу трупоположения в других могилах. К этому погребенному, по мнению Н.Б. Виноградова, относилось скопление украшений № 1, которое, по-видимому, помещалось в небольшой емкости и куда входили, наряду с множеством других украшений, семь бронзовых браслетов. Скопление костей 2 имело форму изогнутой полосы шириной в среднем до 10 см. С ним было связано скопление украшений возле сосуда 3. Украшения были представлены большим количеством бронзовых и пастовых бусин, семью бронзовыми браслетами. Н.Б. Виноградов, опираясь на гипотезу М.П. Грязнова, интерпретировал эти уникальные находки как захоронение праха, помещенного в «куклу». Относительно расположения находок, связанных с первым скоплением кальцинированных костей, Н.Б. Виноградовым сделаны следующие наблюдения и выводы: «Если исходить из этого (наличия «куклы». - C.C.), то становится понятным расположение погребального инвентаря. Накосник ориентирован по линии С3-ЮВ и начинается с крупной обоймы. На скелетах алакульских женщин, погребенных по способу ингумации, начало накосника находится у основания черепа сзади. Стало быть, сосуд 1 и ребра животного (кусок мяса) располагались за головой «куклы», а сосуд 4 и скопление украшений 1 перед лицом ее. Украшение верхнего края обуви низками бронзовых бусин традиционно для алакульских женщин, захороненных по обряду трупоположения. Не случаен, видимо, и факт залегания накосника и низок бус непосредственно на обломках кальцинированных костей» [11. С. 151]. Предположение об использовании в андроновском ритуале «куклы», высказанное в свое время М.П. Грязновым [18. С. 37], сейчас поддерживается многими исследователями [13. С. 67-68].

Однако большая часть погребений по обряду кремации не содержит столь выразительных свидетельств, позволяющих говорить о наличии «куклы». В то же время для андроновского ритуала кремации характерно компактное расположение костей, достаточно определенные границы скоплений остатков кремации, наличие коллективных захоронений с четким разделением на два (Кулевчи-VI, Путиловская Заимка-II, Боровое) или три скопления (Атасу-I, Солнце-Талика). Учитывая находки среди костей разнообразных украшений, обычно нашиваемых на одежду (бус, пронизок, бляшек, подвесок) либо прикрепляемых к головному убору (накосники, височные кольца), можно предположить, что останки помещались в одежду умершего. Е.Е. Кузьмина отмечает, что материалами для одежды андроновцам служили мех, кожа и шерсть [19. С. 156, 160]. М.П. Грязнов сравнивал орнаментацию посуды эпохи бронзы, в том числе андроновской, с орнаментацией кожаной и меховой одежды некоторых коренных народов Южной Сибири и Казахстана и указывал на возможность перенесения орнамента с одежды на посуду [20. С. 58-59]. Учитывая пышную и сложную орнаментацию федоровской погребальной посуды, можно утверждать, что для андроновцев значение одежды вряд ли ограничивалось чисто утилитарным смыслом. Андроновское население могло, к примеру, собирать кремированные кости в мешочек, но помещать его не в куклу, а заворачивать в одежду умершего, расшитую бусами, бляшками и пронизками.

Дополнительным подтверждением существования в андроновской среде особого отношения к кремированным останкам, которые не просто ссыпались в могилу, а помещались в куклу или заворачивались в одежду, является наблюдение алтайских археологов над расположением остатков трупосожжений в погребениях андроновского (федоровского) могильника Рублево-VIII. Скопления кальцинированных костей, занимавшие площадь примерно 50 х 50 см при мощности 5-15 см, располагались несколько разреженно. 
Исследователи считают, что они были перемешаны с какой-то органикой, создававшей дополнительный объем [13. С. 68].

Предположение о помещении кремированных останков в одежду погребенного требует дополнительного обоснования, так как во многих погребениях украшения не обнаружены. Определенную помощь в объяснении этого факта могут оказать этнографические параллели. Например, у казахов традиционная одежда орнаментировалась вышивкой или аппликацией с вышивкой независимо от того, из каких материалов она изготавливалась. А нашивные украшения являлись лишь дополнительным убранством [21. С. 39]. По-видимому, в среде андроновцев-скотоводов основным украшением одежды была аппликация из разноцветных кусочков кожи и лишь в каких-то особых случаях дополнительно использовались нашивные украшения из бронзы. Поэтому в большинстве погребений единственным свидетельством использования одежды в ритуале является компактное расположение кремированных костей.

Аналогии данному способу обращения с кремированными останками имеются в культуре хеттов, сложившейся при участии индоевропейского населения. Среди табличек из Богазкёя есть ряд фрагментов, относящихся к описанию ритуала похорон царя или царицы. Согласно описанию, в первый день совершалась кремация тела. «На второй день, как только рассветает, женщины идут... чтобы собрать кости... Они берут кости серебряной лаппа и погружают их в очищенное масло в серебряном кувшине, затем они вынимают кости из очищенного масла и кладут их на льняной гаџцุарнулли, под который подложена «красивая одежда». Кончив собирать кости, они заворачивают их вместе с льняной тканью в «красивую одежду» и кладут их на стул; а если это женщина, они кладут их на скамеечку... Перед стулом, на котором лежат кости, они ставят стол и угощают горячими хлебами... И всех, кто пришел собирать кости, они потчуют едой... [Затем] они берут кости... и приносят их в его “Каменный дом”» [22. С. 146-147].

Этот текст интересен не только тем, что в нем упоминается о помещении кремированных останков в одежду. Не менее значимым представляется также факт почтительного отношения к кремированным останкам, которые собирали серебряной лопаточкой и погружали в очищенное масло в серебряном кувшине. Исследователи могильника Рублево-VIII обратили внимание на то, что во всех четырех погребениях с кремацией отсутствуют продукты горения. Они считают, что это свидетельствует о том, что кости тщательно выбирались после сожжения тела и отделение костей от остатков погребального костра являлось обязательной частью обряда кремации [13. С. 65].

Следует также отметить, что в хеттском тексте говорится о помещении костей именно в «красивую одежду». Вероятно, ритуальная погребальная одежда, причем как женская, так и мужская, должна была дей- ствительно быть более нарядной. Поэтому обнаружение нашивных украшений в андроновских погребениях с кремацией не обязательно является указанием на женский пол погребенного.

Ocобое отношение к одежде умершего, как к его заместителю, прослеживается в похороннопогребальной обрядности иранских народов. Осетинский обряд сидения мертвых совершался спустя неделю после Нового года и в день Богоявления в семьях, которые в течение предшествующего года потеряли кого-либо из близких. В честь умершего пекли хлеб огромной величины. Затем делали изображение покойного, распялив на палках его одежду, перед которым ставили любимые вещи покойного, чашку и бутылку арака. Существует мнение, что душа на это время вселяется в изображение умершего. В течение дня происходит оплакивание, а затем угощение [23. С. 189]. Известен подобный ритуал и среди других народов Средней Азии и Казахстана. Похоронно-поминальная традиция казахов включает следующий обряд. Части костюма умершего развешивают на веревке в том порядке, в котором одежда используется в повседневном быту. Костюм, осмысляемый как «заместитель умершего» (тул), висит со дня похорон до годичных поминок, затем вещи снимают. Одежда в течение года символизирует своего хозяина и, возможно, является временным вместилищем души покойного [24. С. 69]. Киргизы изготавливали символическое изображение умершего (тул), наряжали в лучшие одежды и хранили в юрте в течение определенного срока. В дни поминок в юрте на веревках развешивались халат, оружие и другие вещи покойного, которые затем убирались. Тул являлся вместилищем души умершего [25. С. 248-250].

В среде андроновского населения антропоморфизированные с помощью одежды кремированные останки также могли рассматриваться как вместилище души покойного. Подтверждением этому служит ритуал последующего кормления умершего, о чем свидетельствует наличие в западной половине погребальной камеры сосудов и ребер животных (чаще всего лошади).

Вероятно, федоровцы сжигали умершего без одежды, так как в противном случае среди кремированных останков должны были бы сохраниться расплавившиеся остатки металлических украшений, нашитых на одежду. Интересные параллели можно провести с иранской традицией. Погребальный обряд иранцев-зороастрийцев отличался от федоровского отсутствием сожжения тела, вместо этого использовалось выставление трупа на солнце с последующим захоронением останков. Однако М. Бойс полагает, что обычай выставления тел заменил у иранцев обряд сожжения, так как огонь они считали слишком священным [26. С. 23-24]. Согласно погребальной традиции древних иранцев-зороастрийцев, в момент выставления трупа на дахме на нем не следовало оставлять одежды. Более того, в Авесте (Видевдат) предусматривалось жестокое наказание за нарушение этой традиции (Vd. VIII. 23-25): «...25. О Создатель 
плотского мира, праведный! Кто одежду оставит поверх покойника, - тканую или кожаную, - такую, как вся одежда мужчины, какое ему наказание? - И сказал Ахура-Мазда: Пусть нанесут ему тысячу ударов конской плетью, тысячу [ударов плетью] “делающей послушными”». По аналогии с иранской традицией можно предположить, что у андроновского населения также не допускалось сожжение умершего в одежде.

В некоторых андроновских погребениях с кремацией обнаружены украшения, которые не связаны с декорированием одежды, а являются самостоятельными элементами костюма. Это бронзовые браслеты, серьги или височные подвески (Солнце-Талика, курган 2; Путиловская Заимка-II, курган 7; Сангру-II, ограда 5; Боровое, ограда V, могила 1; Ур, курган 10 и т.д.). Наличие украшений в таких погребениях не следует однозначно связывать с захоронением женщин. Височные подвески, серьги, браслеты не обязательно являлись женскими украшениями, их могли носить и мужчины. В этом случае представляет интерес еще один аспект вопроса, связанного с антропоморфизацией кремированных останков с помощью украшений.

Не слишком далекой аналогией для данного андроновского ритуала являются изображения на оленных камнях, тем более что ряд исследователей признает наличие андроновских черт в традиции сооружения оленных камней [27. С. 55-57; 28. С. 23-31]. Следует обратить внимание на одну особенность оленных камней, точно подмеченную М.П. Грязновым, - схематизм изображения человека. Изображение лица человека на оленных камнях является большой редкостью. Антропоморфный облик передается деталями одежды (пояс, шапочка), украшениями (серьги, ожерелье, гривна), различными видами оружия. «На столбообразном камне, круглом, овальном или прямоугольном в сечении, совершенно отсутствуют детали человеческой фигуры. Обычно нет и намека на голову, плечи, шею, руки, ноги. Линиями, полосами, кружками намечены лишь части одежды и оружие - шапочка, серьги, ожерелье, пояс. На поясе или около него помещены кинжал, секира, лук в саадаке (горите), оселок и др. На месте лица три или две косые черточки. Часто эти детали изображения доведены до минимума - на лицевой грани плиты кинжал, на правой - секира, на левой саадак или в верхней части камня три черточки, под ними ожерелье, на боковых гранях круглые серьги и больше ничего. Только в единичных случаях более или менее схематично показано на камне лицо человека...» [29. С. 76]. Таким образом, антропоморфизация оленных камней осуществляется по тем же принципам, что и антропоморфизация кремированных останков андроновским населением.

То, что на оленных камнях запечатлен образ мужчины-воина, признается большинством исследователей. Так, М.П. Грязнов отмечает следующее: «Основной сюжет изображений на оленных камнях - фигура воина, вероятно, героя-воина, весьма условно, схематически показанная» [Там же. С. 76]. Вместе с тем на оленных камнях, наряду с предметами вооружения, изображаются украшения (серьги, ожерелье, гривна). Особенно показательным в этом плане является оленный камень из Ушкийн-Увера (Монголия), на котором «изваяна рельефно голова человека и, что замечательно, круглые серьги изображены продетыми в ухо, рельефом же выполненное, - значит, действительно, изображенные на оленных камнях в верхней части их боковых граней круги, это серьги, а не что-либо другое» [Там же. С. 76]. Таким образом, андроновские погребения по способу кремации в сопровождении украшений, как самостоятельных элементов костюма, также могли принадлежать мужчинам-воинам.

Следует отметить, что в древнеиндийской традиции обряд кремации нередко применялся по отношению к воинам. Согласно сведениям из древнеиндийской «Питримедхасутры» Баудхаяны, которые приводятся в работе Е.Е. Кузьминой [30. С. 140] и в рецензии С.В. Кулланды на английское издание этой книги [31. C. 204], если дваждырожденный (к этой категории населения относилась и варна воинов-кшатриев. - C.C.) умирал на чужбине, то собирали 33 кости разных частей скелета, заворачивали их в шкуру черной козы и транспортировали на родину, где и совершали обряд кремации. Таким образом, зафиксированный в андроновских погребениях обряд кремации может свидетельствовать о принадлежности некоторых из этих захоронений воинам, возможно, умершим на чужбине и доставленным на родину для совершения погребального ритуала, включающего сожжение костей.

Дополнительным подтверждением этого предположения являются находки в кургане 7 могильника Урефты-I, который содержал две могилы с кремированными останками. По мнению исследователей, это были два одновременных захоронения, сделанных в общем углублении. В каждой из могил найдено по бронзовому двулезвийному ножу [32. С. 159-161]. В погребении могильника Путиловская Заимка II (курган 7), содержавшем два скопления кремированных останков, обнаружены бронзовый нож с перехватом и два бронзовых разомкнутых височных кольца [16. С. 99].

Вариант 2. Кремированные останки образуют антропоморфную выкладку. В федоровском могильнике Уйтас-Айдос (Центральный Казахстан) в двух каменных ящиках (ограда 2, могилы 4, 5) зафиксированы антропоморфные выкладки из кремированных костей, которые сопровождались сосудами. В могиле 4 выкладка длиной около $30 \mathrm{~cm}$ и толщиной $50 \mathrm{~cm}$ располагалась вдоль южной стенки. В могиле 5 выкладка зафиксирована по центру ящика, она была вытянута по линии 3-В и имела длину около 60 см и толщину 7 см. В юго-западном углу обоих могил найдены сосуды [33. С. 47-48, 57]. Во многом сходный вариант обращения с кремированными останками умершего практиковался ведийскими ариями. Как следует из комментария к «Погребальному гимну», содержащемуся в «Атхарваведе» (XVIII. 4. 16-28), кости, оставшиеся после кре- 
мации, складывали в виде человеческой фигуры. Затем, ориентируясь на стороны света, ставили вокруг этой фигуры блюда с ритуальной пищей и сопровождали обряд произнесением соответствующих ритуальных формул [34. С. 377-378].

Вариант 3. Кремированные останки помещены в сосуд. Подобный способ обращения с кремированными останками встречается достаточно редко. В ограде 3 могильника Шет-І в одном из погребений кремированные кости были помещены в сосуд. В ограде 10 могильника Сангру-II в грунтовой яме найдена нижняя часть сосуда, заполненная кальцинированными костями [4. С. 90, 109]. В могильнике Уйтас-Айдос (могила 4, ограда 2) в юго-западном углу погребальной камеры стоял сосуд, наполовину заполненный утрамбованными кремированными костями, а вдоль южной стенки располагалась антропоморфная выкладка из обожженных костей [33. С. 47]. В могильнике Бурлук-I (Северный Казахстан) в ограде 9 под камнями в ямке найден развал сосуда с пережженными костями [16. С. 87]. В могильнике Сухомесовский (Южное Зауралье) погребение из кургана 6 содержало остатки кремации. В западной части находилось глиняное блюдо с вертикальными выступами-ручками. В блюде в смеси с землей, заполнявшей могилу, найдено около 20 мелких кусочков горелых человеческий костей [35. С. 33]. На территории Западной Сибири в могильнике Старый Тартас-4 в погребении, расположенном во рву кургана 19, обнаружен сосуд, содержащий жженные кости [36. С. 52]. Возможно, помещение кремированных останков в сосуд также являлось средством антропоморфизации. В связи с этим несомненный интерес представляет предположение М.П. Грязнова о возможном перенесении орнамента с одежды на посуду.

Аналогии рассматриваемому способу обращения с кремированными останками имеются в поэме Гомера «Илиада». В гомеровских поэмах нашли отражение многие важные черты реального греческого общества IX-VIII вв. до н.э. (геометрического периода по археологической периодизации) [37. С. 224], т.е. хронологически достаточно близкой эпохи. Данная аналогия представляется вполне уместной с учетом индоевропейского прошлого греческого населения. В «Илиаде» дается описание обряда похорон воинов - Патрокла и Гектора, в ходе которого происходят кремация тела и последующее захоронение кремированных остатков. После сожжения тела Патрокла:

«Сруб угасили, багряным вином поливая пространство Всё, где пламень ходил; и обрушился пепел глубокий; Слезы лиющие, друга любезного белые кости В чашу златую собрали и туком двойным обложили; Чашу под кущу внеся, пеленою тонкой покрыли; Кругом означили место могилы и, бросив основы Около сруба, поспешно насыпали рыхлую землю. Свежий насыпав курган, разошлися они...»

(Илиада, XXIII, 250-257) [38. С. 380].
Обряд захоронения кремированных костей Гектора отличается лишь более сложной конструкцией перекрытия над могильной ямой:

«Сруб угасили, багряным вином оросивши пространство Всё, где огонь разливался пылающий; после на пепле

Белые кости героя собрали и братья, и други,

Горько рыдая, обильные слёзы струя по ланитам.

Прах драгоценный собравши, в ковчег золотой положили,

Тонким обвивши покровом, блистающим пурпуром свежим.

Так опустили в могилу глубокую и, заложивши,

Сверху огромными частыми камнями плотно устлали;

После курган насыпали...»

(Илиада, XXIV, 791-799) [Там же. С. 416].

Таким образом, обряд погребения, представленный в поэмах Гомера, предполагал собирание кремированных останков в сосуд, помещение сосуда в погребальное покрывало, а затем захоронение в могиле. Аналогии с погребальным обрядом из «Илиады» представляют интерес также тем, что этот обряд применялся древними греками по отношению к воинам.

В Греции в геометрический период происходит распространение обряда кремации, а также ваз, расписанных в геометрическом стиле и предназначенных для погребения. В свете предложенной интерпретации захоронения кремированных костей в сосуде, как способа антропоморфизации останков, представляет интерес эволюция этого ритуала в Греции в геометрический период. В работе Л.И. Акимовой отмечается, что постепенно идет процесс разобщения земной и подземной сферы, погребальные расписные вазы начинают выходить из-под земли и становиться надгробиями. При этом урны не исчезают. Погребальный сосуд как бы зримо раздваивается и начинает существовать одновременно в двух разных пространствах - земном и подземном. Примечательно то, что урна с прахом и сосуд-надгробие нередко ставились на одной вертикали, представляя собой как бы две формы одной сущности. Постепенно происходит антропоморфизация сосуда-надгробия, что проявилось не только в увеличении размеров до 1,5 м, но и в уподоблении его формы человеческому телу. В дальнейшем, в VII в. до н.э., на месте таких ваз появляются статуи, передающие образ умершего [39. С. 230-234, 236].

Можно предположить, что у андроновского населения сосуд с кремированными останками также связывался с образом умершего человека и являлся одним из способов антропоморфизации кремированных останков.

Таким образом, кремация уничтожала облик человека, поэтому для воссоздания разрушенного огнем образа андроновское население использовало различные способы антропоморфизации, такие как создание погребальной «куклы»; заворачивание кремированных останков в одежду умершего; помещение в могилу украшений как самостоятельного элемента костюма; захоронение кремированных останков в сосуде. Несмотря на наличие украшений, не следует однозначно определять такие погребения, как женские. Кремация могла применяться 
к мужчинам-воинам, например, погибшим вдали от родины, а украшения являлись деталями погребального костюма, который был более нарядным.

В среде андроновского населения антропоморфизированные различным образом кремированные останки, вероятно, рассматривались как вместилище души покойного. Подтверждением этому служит ритуал последующего кормления умершего, о чем свидетельствует наличие в западной половине погребальной камеры сосудов и ребер животных (чаще всего лошади).

\section{ЛИТЕРАТУРА}

1. Кузьмина Е.Е. Происхождение индоиранцев в свете новейших археологических данных // Этнические проблемы истории Центральной Азии в древности (ІІ тыс. до н.э.). М., 1981. С. 101-125.

2. Кузьмина Е.Е. Классификация и периодизация памятников андроновской культурно-исторической общности // Информационный бюллетень Международной ассоциации по изучению культур Центральной Азии UNESCO. М., 1985. Вып. 9. С. 24-45.

3. Маргулан А.Х., Акишев К.А., Кадырбаев М.К., Оразбаев А.М. Древняя культура Центрального Казахстана. Алма-Ата, 1966.435 с.

4. Кадырбаев М.К., Курманкулов Ж.К. Культура древних скотоводов и металлургов Сары-Арки (по материалам Северной Бетбак-Далы). АлмаАта, 1992. $247 \mathrm{c.}$

5. Усманова Э.Р. Могильник Лисаковский I: факты и параллели. Караганда-Лисаковск, 2005. 232 с.

6. Ковтун И.В. Андроновский могильник Кожа-Бала // Археология, этнография и музейное дело. Кемерово, 1999. С. 27-31.

7. Оразбаев А.М. Северный Казахстан в эпоху бронзы // Труды Института истории, археологии, этнографии АН Каз ССР. 1958. Т. 5. С. 216-294.

8. Абетеков А. Погребения эпохи бронзы могильника Тегирмен-Сай // Краткие сообщения Института археологии. 1963. Вып. 93. С. 93-95.

9. Кожемяко П.Н. Погребения эпохи бронзы в Киргизии // Известия АН КиргССР. Сер. общ. наук. 1960. Т. 2, Вып. 3. С. 81-107.

10. Максимова А.Г. Могильник эпохи бронзы в урочище Тау-Тары // Труды Института истории, археологии, этнографии АН КазССР. 1962. T. 14. C. $37-56$

11. Виноградов Н.Б. Кулевчи VI - новый алакульский могильник в лесостепях Южного Зауралья // Советская археология. 1984. № 3. С. 136-153.

12. Бобров В.В., Михайлов Ю.И. Памятники андроновской культуры Обь-Чулымского междуречья // Рукопись депонирована ИНИОН, № 38518 от 26.06.1989. Кемерово, 1989. 199 с.

13. Кирюшин Ю.Ф., Папин Д.В., Позднякова О.А., Шамшин А.Б. Погребальный обряд древнего населения Кулундинской степи в эпоху бронзы // Аридная зона юга Западной Сибири в эпоху бронзы. Барнаул, 2004. С. 62-85.

14. Уманский А.П. Раскопки в Нижней Суетке в 1964 г. // Краеведческие записки. Барнаул, 1999. Вып. 3. С. 83-99.

15. Блохин А.А. Некоторые особенности андроновского погребального обряда (по материалам могильника Фирсово ХIV) // 275 лет сибирской археологии: матер. XXXVII Региональной археолого-этнографической студенческой конф. (РАЭСК). Красноярск, 1997. С. 51-53.

16. Зданович Г.Б. Бронзовый век Урало-Казахстанских степей. Свердловск. 1988. 184 с.

17. Виноградов Н.Б., Костюков В.П., Марков С.В. Могильник Солнце-Талика и проблема генезиса федоровской культуры бронзового века в Южном Зауралье // Новое в археологии Южного Урала. Челябинск, 1996. С. 131-150.

18. Грязнов М.П. Пастушеские племена Средней Азии в эпоху развитой и поздней бронзы // Краткие сообщения Института археологии. 1970. Вып. 122. С. 35-38.

19. Кузьмина E.E. Откуда пришли индоарии? Материальная культура племен андроновской общности и происхождение индоиранцев. М., 1994. $464 \mathrm{c}$

20. Кирюшин Ю.Ф. Особенности погребального обряда и погребальной посуды андроновской культуры // «Моя избранница наука, наука, без которой мне не жить...». Барнаул, 1995. С. 58-75.

21. Шевцова А.А. Казахский традиционный свадебный костюм (XIX - начало XX века) // Среднеазиатский этнографический сборник. М., 2006. Вып. V. C. 33-46.

22. Герни O.P. Хетты. М., 1987. 234 с.

23. Дюмезиль Ж. Скифы и нарты. М., 1990. 229 с.

24. Коновалов А.В. Одежда в похоронно-поминальной обрядности казахов // Вешь в контексте культуры : материалы науч. конф. СПб., 1994. С. 68-69.

25. Шишло Б.П. Среднеазиатский тул и его сибирские параллели // Домусульманские верования и обряды в Средней Азии. М., 1975. С. $248-260$.

26. Бойс М. Зороастрийцы. Верования и обычаи. М., 1987. 316 с.

27. Бобров В.В. К проблеме вертикально установленных объектов в погребениях эпохи бронзы Сибири и Казахстана // Северная Евразия от древности до Средневековья : тез. конф. к 90-летию со дня рождения М.П. Грязнова. СПб., 1992. С. 54-57.

28. Савинов Д.Г. Ранние кочевники Верхнего Енисея. Археологические культуры и культурогенез. СПб., 2002.204 с.

29. Грязнов М.П. О монументальном искусстве на заре скифо-сибирских культур в степной Азии // Археологический сборник Государственного Эрмитажа. Л., 1984. Вып. 25. С. 76-82.

30. Кузьмина Е.Е. Арии - путь на юг. М., 2008. 558 с.

31. Кулланда С.В. Рец. на: Е.E. Kuzmina. The Origin of the Indo-Iranians / ed. by J.P. Mallory. Leiden Indo-European Etymological dictionary Series / ed. By Lubotsky. Vol. 3. Leiden-Boston: Brill, 2007. XVIII + 762 р. // Вестник древней истории. 2010. № 3. С. $202-211$.

32. Стефанов В.И., Днепров С.А., Корочкова О.И. Курганы федоровского типа могильника Урефты I // Советская археология. 1983. C. $155-165$.

33. Усманова Э.Р., Варфоломеев В.В. Уйтас-Айдос - могильник эпохи бронзы // Вопросы археологии Казахстана. Алматы-М., 1998. Вып. 2. C. 46-60.

34. Атхарваведа. Избранное / пер., коммент. и вступ. статья Т.Я. Елизаренковой. М., 1995. 406 с.

35. Андроновская культура. Памятники западных областей // Свод археологических источников. 1966. Вып. В $3-2.144$ с.

36. Молодин В.И., Новиков А.В., Жемерикин Р.В. Могильник Старый Тартас-4 (новые материалы по андроновской историко-культурной общности) // Археология, этнография и антропология Евразии. 2002. № 3 (11). С. 48-62.

37. История Европы. Т. 1. Древняя Европа. М., 1988. 704 с.

38. Гомер. Илиада // Гомер. Илиада / пер. с древнегреч. Н. Гнедича; Одиссея / пер. с древнегреч. В. Жуковского. М., 1996. С. $23-416$.

39. Акимова Л.И. Об отношении геометрического стиля к обряду кремации // Исследования в области балто-славянской духовной культуры. Погребальный обряд. М., 1990. С. 228-237.

Sotnikova Svetlana $V$. Branch of Tyumen State University in Tobolsk (Tobolsk, Russian Federation). E-mail: svetlanasotnik@mail.ru TO THE ISSUE OF ANTHROPOMORPHIZATION OF CREMATED REMAINS IN THE FUNERAL RITE OF THE POPULATION ANDRONOVO CULTURAL-HISTORICAL COMMUNITY.

Keywords: The Bronze Age; Andronovo cultural-historical community; funeral rite; cremation; anthropomorphism.

In the Bronze Age the Andronovo cultural-historical community occupied vast expanses of steppe and forest-steppe zone of the Southern Urals, Kazakhstan and Western Siberia. The Problem of the ethnicity of Andronovo population is controversial. Many researchers 
refer the Andronovo population to the Indo-Iranians. This allows to draw to the interpretation of the Andronovo material written sources of peoples with Indo-European roots (ancient Iranian, Indic, Hittite, Greek, etc.). One of the striking elements of the funeral rite Andronovo (Fedorovo) population was the ritual burning of the deceased. The rite of cremation was carried out on the side, and compact accumulations of calcified bones placed in the burial. Materials of Andronovo burials with cremated remains attract attention because they allow us to trace the emergence of different ways of anthropomorphization of cremated remains. We can distinguish three main variants: 1) cremated remains are arranged in the form of compact accumulations and accompanied by ornaments; 2) cremated remains are given anthropomorphic form; 3) cremated remains are placed in a vessel. In the first variant the anthromorphization was happening, probably, by creating a funeral "doll", or by placing the cremated remains in the clothes of the deceased, on which were sewed embellishments. Despite the presence of embellishments should not uniquely determine such burial as female. Cremation could be applied to a male warrior, for example, who died far from home, and the embellishments are the details of the funeral suit, which was more rich. In the third variant, means of anthropomorphization was placing cremated remains in the vessel. In this regard the particular interest is the M.P. Gryaznov's assumption about the possibility of transferring ornament from clothes on the vessels. Analogies to considered way handling with cremated remains there are in Homer's "Iliada". Also these analogies are interesting that this rite was used by the ancient Greeks in relation to the warriors. Cremation destroyed human form, therefore to reconstruct destroyed by fire image Andronovskoe people used different ways anthropomorphization. In the environment of the Andronovo population cremated remains, anthropomorphizated by different ways, probably, was regarded as the receptacle of the soul of the deceased. This is confirmed by the subsequent ritual feeding of the deceased, as evidenced by the presence vessels and ribs of animals (mostly horses) in the Western half of the burial chamber.

\section{REFERENCES}

1. Kuz'mina E.E. Proiskhozhdenie indoirantsev $v$ svete noveyshikh arkheologicheskikh dannykh [The origin of the Indo-Iranians in the light of the latest archaeological data]. In: Etnicheskie problemy istorii Tsentral'noy Azii v drevnosti (II tys. do n.e.) [The ethnic problems of history of Central Asia in ancient times (the 2nd millennium BC.)]. Moscow, 1981, pp. 101-125.

2. Kuz'mina E.E. Klassifikatsiya i periodizatsiya pamyatnikov andronovskoy kul'turno-istoricheskoy obshchnosti [Classification and periodization monuments Andronovo cultural-historical community]. Informatsionnyy byulleten' Mezhdunarodnoy assotsiatsii po izucheniyu kul'tur Tsentral'noy Azii UNESCO - International Association for the Study of the Cultures of Central Asia, UNESCO, 1985, no. 9, pp. 24-45.

3. Margulan A.Kh., Akishev K.A., Kadyrbaev M.K., Orazbaev A.M. Drevnyaya kul'tura Tsentral'nogo Kazakhstana [The ancient culture of Central Kazakhstan]. Alma-Ata: Nauka Publ., 1966. 435 s.

4. Kadyrbaev M.K., Kurmankulov Zh.K. Kul'tura drevnikh skotovodov i metallurgov Sary-Arki (po materialam Severnoy Betbak-Daly) [The culture of ancient cattle-breeders and metallurgists of Sary-Arka (as exemplified by North Betbak Dala)]. Alma-Ata: Gylym Publ., 1992. 247 p.

5. Usmanova E.R. Mogil'nik Lisakovskiy I: fakty i paralleli [The burial Lisakovskiy I: facts and parallels]. Karaganda-Lisakovsk: Karaganda State University Publ., Lisakovsk Museum of history and Pulture Publ., 2005. 232 p.

6. Kovtun I.V. Andronovskiy mogil'nik Kozha-Bala [The Andronov cemetery Kozha-Bala]. In: Bobrov V.V. (ed.) Arkheologiya, etnografiya i muzeynoe delo [Archaeology, Ethnology and Museums]. Kemerovo: Kemerovo State University Publ., 1999, pp. 27-31.

7. Orazbaev A.M. Severnyy Kazakhstan v epokhu bronzy [Northern Kazakhstan in the Bronze Age]. Trudy Instituta istorii, arkheologii, etnografii AN Kaz SSR, 1958, vol. 5, pp. 216-294.

8. Abetekov A. Pogrebeniya epokhi bronzy mogil'nika Tegirmen-Say [The burials of the Bronze Age of the burial Tegirmen Sai]. Kratkie soobshcheniya instituta arkheologii, 1963, vol. 93, pp. 93-95.

9. Kozhemyako P.N. Pogrebeniya epokhi bronzy v Kirgizii [The Bronze Age burials of Kyrgyzstan]. Izvestiya AN KirgSSR, 1960 , vol. 2 (3), pp. 81-107.

10. Maksimova A.G. Mogil'nik epokhi bronzy v urochishche Tau-Tary [The Bronze Age burial in Tau Tara]. Trudy Instituta istorii, arkheologii, etnografii AN KazSSR, 1962, vol. 14, pp. 37-56.

11. Vinogradov N.B. Kulevchi VI - novyy alakul'skiy mogil'nik v lesostepyakh Yuzhnogo Zaural'ya [Kulevchi VI - a new Alakul burial in the forest steppe of South Ural]. Sovetskaya arkheologiya, 1984, no. 3, pp. 136-153.

12. Bobrov V.V., Mikhaylov Yu.I. Pamyatniki andronovskoy kul'tury Ob'-Chulymskogo mezhdurech'ya [Monuments of Andronovo culture of ObChulym interfluve]. Kemerovo, 1989. 199 s.

13. Kiryushin Yu.F., Papin D.V., Pozdnyakova O.A., Shamshin A.B. Pogrebal'nyy obryad drevnego naseleniya Kulundinskoy stepi v epokhu bronzy [Funeral rites of the ancient population Kulunda steppes in the Bronze Age]. In: Kiryushin Yu.F. (ed.) Aridnaya zona yuga Zapadnoy Sibiri v epokhu bronzy [The Arid Zone of the south of Western Siberia in the Bronze Age]. Barnaul: Altai State Univeristy Publ., 2004, pp. 62-85.

14. Umanskiy A.P. Raskopki v Nizhney Suetke v 1964 g. [Excavations in Nizhnyaya Suetka in 1964]. Kraevedcheskie zapiski, 1999, vol. 3, pp. 83-99.

15. Blokhin A.A. [Some features of Andronovo Burial rite (based on Burial Firsovo XIV)]. 275 let sibirskoy arkheologii: mater. XXXVII Regional'noy arkheologo-etnograficheskoy studencheskoy konf. (RAESK) [275 years of Siberian archeology. Proc. of the 27th Regional Archaeological and Ethnographic Student Conference (RAESK)]. Krasnoyarsk, 1997, pp. 51-53. (In Russian).

16. Zdanovich G.B. Bronzovyy vek Uralo-Kazakhstanskikh stepey [The Bronze Age of Ural-Kazakhstan steppes]. Sverdlovsk, 1988. 184 p.

17. Vinogradov N.B., Kostyukov V.P., Markov S.V. Mogil'nik Solntse-Talika i problema genezisa fedorovskoy kul'tury bronzovogo veka v Yuzhnom Zaural'e [Burial Sun-Talika and the genesis of Fedorov culture of the Bronze Age in the Southern Urals]. In: Grigoriev S.A. (ed.) Novoe $v$ arkheologii Yuzhnogo Urala [The new data in the archaeology of Southern Urals]. Chelyabinsk: Rifei Publ., 1996, pp. 131-150.

18. Gryaznov M.P. Pastusheskie plemena Sredney Azii v epokhu razvitoy i pozdney bronzy [The sheperds' tribes of Central Asia in the Late Bronze Age]. Kratkie soobshcheniya instituta arkheologii, 1970, vol. 122, pp. 35-38.

19. Kuz'mina E.E. Otkuda prishli indoarii? Material'naya kul'tura plemen andronovskoy obshchnosti i proiskhozhdenie indoirantsev [Where did the Indo-Aryans come from? The material culture of Andronovo tribes and the origin of Indo-Iranians]. Moscow: Kalina Publ., 1994. 464 p.

20. Kiryushin Yu.F. Osobennosti pogrebal'nogo obryada i pogrebal'noy posudy andronovskoy kul'tury [The funeral ceremony and burial dishes of Andronovo culture]. In: Gracheva G.N., Vasil'ev V.I., Kiryushin Yu.F., Maloletko A.M., Chindina L.A. "Moya izbrannitsa nauka, nauka bez kotoroy mne ne zhit'” [My fiancee is science, the science without which I can not live ...']. Barnaul: Altai State University Publ., 1995, pp. 58-75.

21. Shevtsova A.A. Kazakhskiy traditsionnyy svadebnyy kostyum (XIX-nachalo XX veka) [The Kazakh traditional wedding dress (the 19th - early 20th century)]. In: Abashin S.N., Bushkov V.I. (eds.) Sredneaziatskiy etnograficheskiy sbornik [Central Asian ethnographic collection]. Moscow: Nauka Publ., 2006. Issue 5, pp. 33-46.

22. Gurney O.R. Khetty [The Hittites]. Translated from English by N.M. Lozinskiy, N.A. Tolstoy. Moscow: Nauka Publ., 1987. 234 p.

23. Dumézil G. Skify i narty [Scythians and Narts]. Translated from French by A.Z. Almazova. Moscow: Nauka Publ., 1990. 229 p.

24. Konovalov A.V. [Clothing and funeral rites of Kazakhs]. Veshch'v kontekste kul'tury. Materialy nauchnoy konferentsii [The thing in the context of culture. Proc. of the Conference]. St. Petersburg, 1994, pp. 68-69. (In Russian).

25. Shishlo B.P. Sredneaziatskiy tul i ego sibirskie paralleli [Central Asian and Siberian quivars]. In: Snesarev G.P., Basilov V.N. (eds.) Domusul'manskie verovaniya i obryady v Sredney Azii [Pre-Islamic beliefs and practices in Central Asia]. Moscow: Nauka Publ., 1975, pp. 248-260. 
26. Boyce M. Zoroastriytsy. Verovaniya i obychai [Zoroastrians. Beliefs and practices]. Translated from English by I.N. Steblin-Kamenskiy. Moscow: Nauka Publ., 1987. 316 p.

27. Bobrov V.V. [On the problem of vertically mounted objects in the Bronze Age burials of Siberia and Kazakhstan]. Severnaya Evraziya ot drevnosti do srednevekov'ya. Tez. konf. k 90-letiyu so dnya rozhdeniya M.P. Gryaznova [Northern Eurasia from antiquity to the Middle Ages. Proc. of the Conference devoted to the 90th anniversary of M.P. Gryaznov]. St. Petersburg, 1992, pp. 54-57.

28. Savinov D.G. Rannie kochevniki Verkhnego Eniseya. Arkheologicheskie kul'tury i kul'turogenez [Early nomads in the Upper Yenisei. Archaeological cultures and cultural genesis]. St. Petersburg: St. Petersburg State University Publ., 2002. 204 p.

29. Gryaznov M.P. O monumental'nom iskusstve na zare skifo-sibirskikh kul'tur $v$ stepnoy Azii [On the monumental art at the dawn of the ScythianSiberian steppe cultures in Asia]. In: Arkheologicheskiy sbornik Gosudarstvennogo Ermitazha [The archaeological collection of the State Hermitage]. Leningrad, 1984. Issue 25, pp. 76-82.

30. Kuz'mina E.E. Arii - put' na yug [The Aryan - way to the south]. Moscow: Letniy sad Publ., 2008. 558 p.

31. Kullanda S.V. E.E.Kuzmina. The Origin of the Indo-Iranians. Leiden Indo-European Etymological dictionary Series. Ed. By Lubotsky. Vol.3. Leiden-Boston: Brill, 2007. XVIII + 762 p. Vestnik drevney istorii - Journal of Ancient History, 2010, no. 3, pp. 202-211. (In Russian).

32. Stefanov V.I., Dneprov S.A., Korochkova O.I. Kurgany fedorovskogo tipa mogil'nika Urefty I [The Fedorov type of burial mounds in Urefty I]. Sovetskaya arkheologiya, 1983, no. 1, pp. 155-165.

33. Usmanova E.R., Varfolomeev V.V. Uytas-Aydos - mogil'nik epokhi bronzy [Uytas-Aidos - the burial of the Bronze Age archeology]. Voprosy arkheologii Kazakhstana, 1998, no. 2, pp. 46-60.

34. Atharvaveda. Izbrannoe [Selected works]. Translated by T.Ya. Elizarenkova. Moscow: Vostochnaya literatura Publ., 1995. 406 p.

35. Andronovskaya kul'tura. Pamyatniki zapadnykh oblastey [The Andronovo culture. The Monuments of Western regions]. In: Svod arkheologicheskikh istochnikov [The collection of archaeological sources]. Moscow, 1966, vol. V (3-2). $144 \mathrm{p}$

36. Molodin V.I., Novikov A.V., Zhemerikin R.V. Mogil'nik Staryy Tartas-4 (novye materialy po andronovskoy istoriko-kul'turnoy obshchnosti) [The old burial site Tartas-4 (new materials for the Andronovo historical and cultural community)]. Arkheologiya, etnografiya i antropologiya Evrazii Archaeology, Ethnology \& Anthropology of Eurasia, 2002, no. 3 (11), pp. 48-62.

37. Istoriya Evropy. T. 1. Drevnyaya Evropa [The history of Europe. Vol. 1. Ancient Europe]. Moscow, 1988.704 p.

38. Homer. Iliada [Iliad]. Translated from ancient Greek by N. Gnedich. Moscow, 1996, pp. 23-416.

39. Akimova L.I. Ob otnoshenii geometricheskogo stilya k obryadu krematsii [On the relation of the geometric style to the cremation rite]. In: Nevskaya L.G. (ed.) Issledovaniya v oblasti balto-slavyanskoy dukhovnoy kul'tury. Pogrebal'nyy obryad [The research in Balto-Slavic spiritual culture. Funeral rites]. Moscow: Nauka Publ., 1990, pp. 228-237. 